J. Dairy Sci. 92:645-656

doi:10.3168/jds.2008-1153

(c) American Dairy Science Association, 2009.

\title{
Influence of weaning method on health status and rumen development in dairy calves
}

\author{
B. A. Roth, ${ }^{1}$ N. M. Keil, $†$ L. Gygax, $†$ and E. Hillmann* \\ *Eidgenössische Technische Hochschule Zürich (ETH Zurich), Institute of Animal Sciences, Physiology and Behaviour, 8092 Zurich, Switzerland \\ †Federal Veterinary Office, Centre for Proper Housing of Ruminants and Pigs, Agroscope Reckenholz-Taenikon Research Station ART, Taenikon, \\ 8356 Ettenhausen, Switzerland
}

\section{ABSTRACT}

In the artificial rearing of dairy calves, the same feeding plan is applied to all animals during the milkfeeding period, with individual differences attributable to development or health status rarely considered. The aim of this study was 1) to analyze whether the parameters of feeding behavior automatically recorded by a feeding computer and weight gain are suitable for predicting the health status and rumen development of male dairy calves, and 2) to compare a conventional weaning method (end of milk provision at 12 wk of age, $\mathrm{n}=23$ calves) with a concentrate-dependent weaning method (with reduction in the milk amount depending on the consumption of concentrate, $n=24$ ). The health status of each animal was evaluated daily by a scoring list (health score), and body temperature was measured automatically during each milk intake. In addition, the number of veterinary treatments per calf was recorded. Rumen development was assessed by measuring rumen papillae in 8 rumen areas after slaughter $(\mathrm{n}=24$, half of each treatment group). During the milk-feeding period, body temperature was elevated $\left(\geq 39.5^{\circ} \mathrm{C}\right)$ on 40.8 and $43.2 \%$ of all days for calves on the concentrate-dependent weaning method and the conventional weaning method, respectively. Hay and concentrate intake (but not milk intake) and weight gain were clearly affected by health status. In addition, health score and the probability of being treated by a veterinarian were significantly related to decreases in concentrate consumption. During the milk-feeding period, increased body temperature, an increased number of veterinary treatments, and decreases in milk consumption were all associated with reduced weight gain. Calves on the concentrate-dependent weaning method were weaned at an average age of $76 \mathrm{~d}$, which was significantly shorter than the age at the end of milk provision for conventionally fed calves (84 d). Weight gain and health status did not differ between

Received March 5, 2008

Accepted September 16, 2008.

${ }^{1}$ Corresponding author: Beatrice-Roth@ethz.ch treatment groups. Weight gain was positively associated with papillae length. A treatment effect on rumen development could not be found. We conclude that the concentrate-dependent weaning method allows a faster physiological development without any negative impact on rumen development, weight gain, or health status; we therefore recommend its use in practice.

Key words: dairy calf, health status, rumen development, weaning

\section{INTRODUCTION}

In artificial rearing of dairy calves, the period during weaning (until the end of milk provision) is critical in relation to disease problems (Curtis et al., 1988; Svensson et al., 2003). Calves at this age are most at risk for respiratory diseases and diarrhea (e.g., Radostits, 2001; Svensson et al., 2003; Lundborg et al., 2005). Regrouping of calves from different locations, as is routinely done when buying calves for fattening, poses an especially great risk for these young animals, which do not yet have a functioning immune system (Radostits, 2001). Diseases have a negative impact on the animals in terms of welfare and are undesirable for economical reasons.

To allow for a fast veterinary intervention if needed, immediate detection of deviations from the normal health status is required. Assessment of the health status of animals is complex, however, as shown by the variety of methods described in the literature (e.g., Gibb et al., 2000; Lundborg et al., 2005; Svensson and Jensen, 2007), and standardization for administration of a veterinary treatment is often not given. As group size increases and the use of computer-controlled milkfeeding systems become more common in practice (Hepola, 2003), exact and reliable methods are needed for surveying health status automatically.

The transition from "pseudo-monogastric" digestion to ruminant digestion is a delicate process for the young calf, and mechanisms controlling ruminal differentiation are not entirely understood (Baldwin et al., 2004). Rumen development is known to be greatly affected 
by diet (e.g., Tamate et al., 1962). Conventional milkfeeding plans consider only the age of the calves as the sole criterion for ceasing milk provision. It is plausible that calves differ genetically in their disposition for rumen development. Additionally, in the case of illness, feeding plans need to be adjusted because physiological development is slowed during illness (Radostits, 2001). It has often been observed that in farming practice, weight gain after the end of milk provision is reduced in some calves (Kirchgessner, 2004), most likely because the intake of dry food is not yet sufficient at the time milk provision is stopped. This simply reflects the fact that conventional feeding plans satisfy the nutritional needs of the "average calf," but not of every individual calf.

We previously demonstrated that compared with a conventional weaning method, a concentrate-dependent weaning method reduced the number of calves exhibiting cross-sucking and improved their weight gain (Roth et al., 2008). The concentrate-dependent weaning method is based on the concept that milk allowance should be reduced in close relationship to the solid food intake of the individual calf. This practice aims to cover the nutritional needs of each individual calf at any time during the milk-feeding period, and to ensure that calves are not weaned from milk until they are able to feed on solid food only.

The aim of this study was to analyze whether the parameters of feeding behavior automatically recorded by a feed intake-monitoring computer would be suitable to predict the health status and rumen development of male dairy calves. It was also hypothesized that the concentrate-dependent weaning method would improve health status, weight gain, and rumen development compared with the conventional weaning method.

\section{MATERIALS AND METHODS}

\section{Animals and Housing}

The experiment was performed between May and November 2005 at Agroscope Reckenholz-Taenikon Research Station ART (Ettenhausen, Switzerland) in 2 replicates and included a total of 47 male dairy calves. The calves were purchased from 30 Swiss dairy farms (41 calves), except for 6 calves that were born at the research facility. The calves (26 Swiss Brown, 14 Red Holstein, and 7 Holstein-Friesian) were assigned to the 2 treatment groups (conventional weaning vs. concentrate-dependent weaning) according to their age and weight at the time of purchase, breed, feeding management (e.g., milk allowance, feeding of concentrate or hay), and housing system (e.g., housing outdoors in huts or in indoor pens) at their farm of origin. Two matching calves were each randomly assigned to 1 of the 2 treatments to create 2 comparable treatment groups. The animals were investigated in 2 replicates (first replicate: 23 calves; second replicate: 24 calves). In each replicate, half the animals were weaned by the conventional weaning method (11 + 12 calves), and the other half were weaned by the concentrate-dependent weaning method ( $12+12$ calves $)$.

The average age at grouping was $30.1( \pm 1.5) \mathrm{d}$. Calves were kept on deep litter in the same pen, measuring $48 \mathrm{~m}^{2}\left(2 \mathrm{~m}^{2} /\right.$ animal $)$, which was open on one side without access to a barnyard or pasture. Hay and water were available ad libitum. The calves were fed milk replacer and concentrate by a computer-controlled milk feeder and a computer-controlled concentrate feeder, respectively (FA Foerster-Technik GmbH, Engen, Germany). They had access to the 2 feeders at all times. A transponder in the neckband allowed each calf to be identified individually. The automatic milk and concentrate feeding stalls were equipped with a self-enclosing mechanism (according to the method of Weber and Wechsler, 2001) that prevented displacement of the feeding calf by others.

\section{Weaning Methods and Recording of Feeding Behavior}

Conventional Weaning. The feeding plan for the 23 conventionally weaned calves reflected a conventional weaning method common in Switzerland, beginning with $6 \mathrm{~L}$ of milk daily from 3 wk of age onward. The amount of milk was reduced continuously between 8 and 12 wk of age, and milk provision was stopped at the end of 12 wk of age (Swiss Federal Research Station for Animal Production, 1999). Conventionally weaned calves had access to concentrate according to their calculated nutritional need, but the concentrate consumption of the individual calf did not affect milk allowance.

Concentrate-Dependent Weaning. The 24 calves weaned based on the concentrate-dependent plan also began with $6 \mathrm{~L}$ of milk daily. Thereafter, each calf was fed according to its own individual feeding plan (Figure 1). The daily milk allowance was based on the average amount of concentrate consumed over the last $4 \mathrm{~d}$. Milk quantities were rounded up to the nearest half- or fullliter level. As soon as a calf consumed more than $700 \mathrm{~g}$ of concentrate per day for $4 \mathrm{~d}$ in a row, the reduction of milk began. When a calf consumed more than 2,000 $\mathrm{g}$ of concentrate per day for $4 \mathrm{~d}$ in a row, milk feeding was stopped altogether. The relationship between milk amount and concentrate amount was linear. For example, at a consumption level of 1,500 g of concentrate, $3 \mathrm{~L}$ of milk was provided. In the case of reduced 


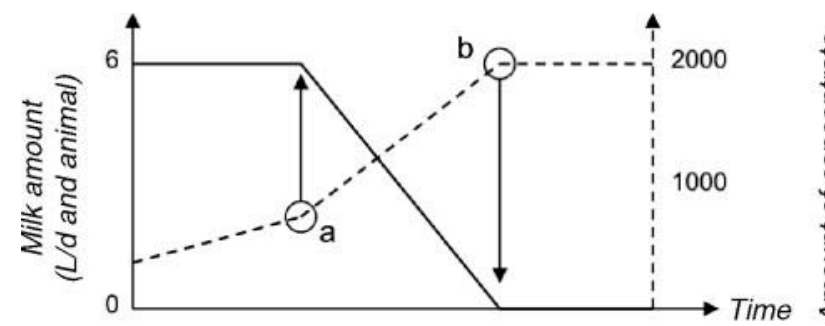

Figure 1. Concentrate-dependent weaning method. Reduction of milk was regulated by concentrate consumption. a) Intake of $700 \mathrm{~g}$ of concentrate daily over a 4 -d period triggered the start of milk reduction. b) Intake of 2,000 $\mathrm{g}$ of concentrate daily over a 4 -d period defined the end of milk provision.

concentrate consumption, the amount of milk was increased again accordingly. In contrast to conventionally weaned calves, in calves on the concentrate-dependent weaning plan, the duration of the milk-feeding period, and therefore the age at the end of milk provision, was determined by the individual food intake of the calf.

Feeding Behavior. Daily concentrate and milk consumption were recorded automatically by the feeding computer. For statistical analysis, the average daily amounts of consumed concentrate and milk were calculated for each animal. In addition, the decreases in concentrate and milk consumption were calculated for each animal during the milk-feeding period. A decrease in concentrate consumption was noted when the amount of concentrate eaten by a calf was lower by $150 \mathrm{~g}$ or more than the amount on the previous day. Decreases in milk consumption were defined analogously, with the threshold value being $1 \mathrm{~L}$ in this case.

To assess hay consumption, each animal was observed directly on 2 consecutive days $1 \mathrm{wk}$ after grouping, $1 \mathrm{wk}$ before milk provision was stopped (at a milk allowance of 1 to $2.5 \mathrm{~L}$ ), and $1 \mathrm{wk}$ after the end of milk provision from 0600 to $0900 \mathrm{~h}$ and from 1700 to $2000 \mathrm{~h}$ (being the main feeding times according to Keil and Langhans, 2001). The duration of hay feeding was recorded and the mean duration per observation day was calculated for each calf.

\section{Health}

Daily Health Scoring and Veterinary Treatments. The health status of each calf was evaluated daily by 2 trained caretakers according to a scoring list (Table 1). General condition; state of the eyes, nose, ears, and navel; incidence of cough; and dirtiness caused by feces were evaluated. Points from 0 to 2 were assigned such that greater scores corresponded to a worse health status. The points for each animal were summed (health score) and all veterinary treatments
Table 1. Scoring list of daily health assessment (health score)

\begin{tabular}{lc}
\hline Parameters evaluated & Points, n \\
\hline General condition & \\
Normal condition & 0 \\
Slightly impaired & 1 \\
Severely impaired & 2 \\
Incidence of cough & \\
$\quad$ None & 0 \\
Sporadic coughing & 1 \\
Repeated coughing & 2 \\
Dirtiness caused by feces & \\
Inconspicuous & 0 \\
Dry dirtiness & 1 \\
Moist or wet dirtiness & 2 \\
Ears & \\
Normal & 0 \\
Lop-eared & 1 \\
Eyes & \\
Inconspicuous & \\
$\quad$ Slight watering & 0 \\
Nose, nasal discharge & 1 \\
No discharge & \\
Watery discharge or dry nose & \\
Purulent discharge & 0 \\
Navel & \\
Snconspicuous & \\
Swollen, without discharge & \\
\hline &
\end{tabular}

for infectious diseases were recorded and summed for each calf for statistical analysis.

Automatic Measurement of Body Temperature. The artificial teat of the milk feeder was equipped with a sensor to measure the temperature on the surface of the tongue automatically during milk intake (FA Foerster-Technik $\mathrm{GmbH}$ ). Rectal temperature is, on average, 0.2 to $0.3^{\circ} \mathrm{C}$ higher than the temperature on the tongue surface when measured by this system (Harsch, 2002). Therefore, a temperature on the tongue surface of $39.5^{\circ} \mathrm{C}$ or higher is most likely related to fever. On the basis of these measurements, the proportion of days with a temperature of $39.5^{\circ} \mathrm{C}$ or higher (according to the threshold value for fever in Rademacher, 2003) was calculated for each calf for the milk-feeding period. Caretakers were not aware of the automatically measured body temperatures to avoid any influence on their health score.

Because body temperature could not be measured automatically after stopping milk provision, all variables for the analysis of health (proportion of days $\geq 39.5^{\circ} \mathrm{C}$, health score, number of veterinary treatments) were evaluated only during the milk-feeding period.

\section{Calculation of Weight Gain}

All calves were weighed once weekly. The daily weight gain of each animal was then calculated on the basis of weekly weighings. 


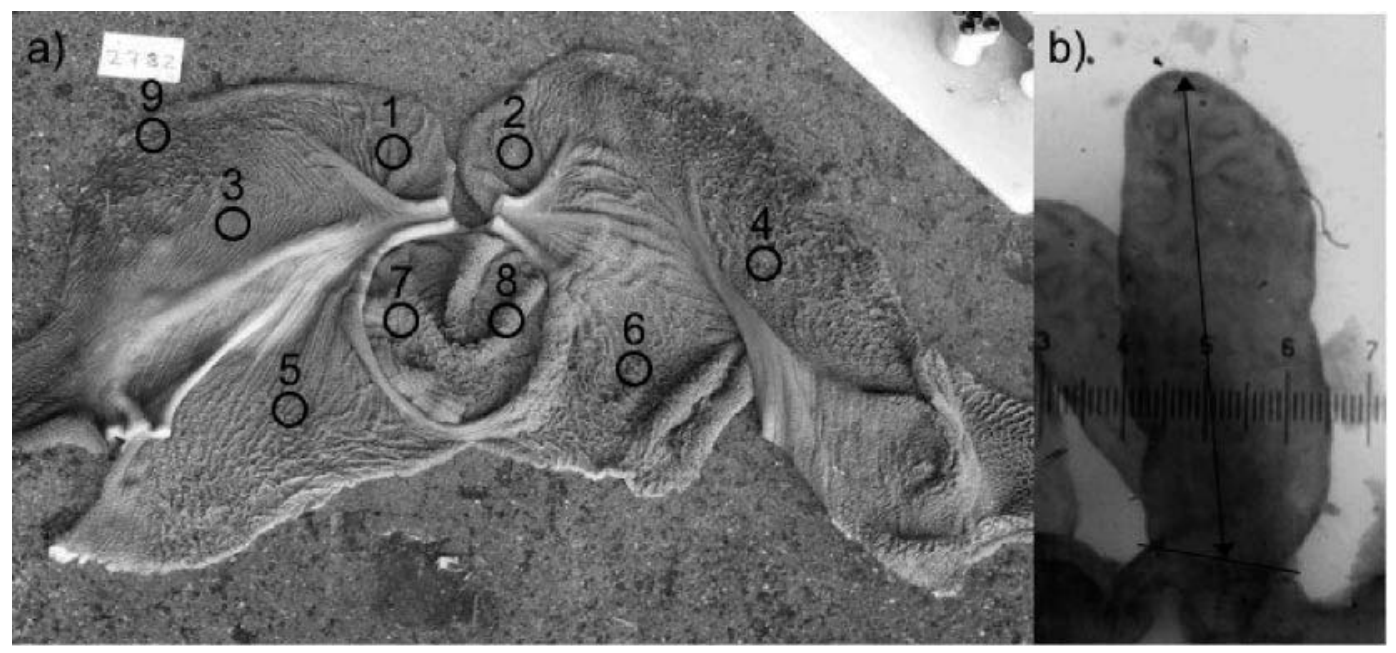

Figure 2. a) Rumen after opening (emptied and cleaned with cold water). Sample areas are marked by an open circle $(\bigcirc)$ and numbered according to Table 2 . b) Rumen papillae (20× magnification).

\section{Rumen Development}

Twenty-four (16 Swiss Brown and 8 Red Holstein) of the 47 calves were killed via captive bolt stunning and exsanguination $3 \mathrm{wk}$ after the end of milk provision to analyze rumen development (6 calves on concentratedependent weaning and 6 calves on conventional weaning of the first and second replicates, respectively). A time span of 3 wk after the end of milk provision was needed for behavioral observations for another project. Rumen sampling was modified according to the method of Lesmeister et al. (2004) because animals in our study were older ( 15 wk vs. 4 to $6 \mathrm{wk}$ ). Immediately after slaughtering, the rumen was placed on its left side. A first incision was made starting at the end of the esophagus along the gastric groove (sulcus ventriculi) to the ostium reticulo-omasicum. The incision then proceeded along the center line of the reticulum over the dorsal sac to the end of the dorsal blind sac. The ventral blind sac was kept intact. At the caudal end of the ventral sac, a second incision was made at the ventral center line that proceeded to the middle of the reticulum. The rumen was then opened, emptied, rinsed with cold water, and laid down flat on a planar surface Tissue samples were taken from 9 different rumen areas (Table 2 and Figure 2a).

Four $1-\mathrm{cm}^{2}$ sections were taken from each area. The tissue samples were immediately put into a $4 \%$ formaldehyde solution. The lengths of 5 papillae of each sample were measured by using a binoculars $(20 \times$ magnified; Leica Wild M10, Leica Microsystems, Wetzlar, Germany; Figure 2b). The papillae of area 9 (middle of the dorsal sac) could not be analyzed because they were too short to be measured. Thus, the lengths of 5 papillae in 4 samplings of 8 areas for each animal were used for statistical analysis.

\section{Statistical Analysis}

To account for the hierarchical design (calf nested in replicate, repeated measurements per calf), generalized linear mixed-effects models were used. To find an appropriate final model, a stepwise-backward selection was used for all models, with the exception of the logistic model for veterinary treatments (with the dichotomous response variable treatment yes/no, model B),

Table 2. Localization of the sample areas in the rumen, and position of sampling within the sample area

\begin{tabular}{|c|c|c|}
\hline Area no. & Rumen area & Exact position of sampling within area \\
\hline 1 & Dorsal blind sac, right & One finger space to the pila coronaria dorsalis \\
\hline 2 & Dorsal blind sac, left & One finger space to the pila coronaria dorsalis \\
\hline 3 & Dorsal sac, right & Two finger spaces to the pila accessoria sinister \\
\hline 4 & Dorsal sac, left & Two finger spaces to the pila accessoria dexter \\
\hline 5 & Ventral sac, right & Middle of the right side (same distance to the pila longitudinalis dexter and the pila coronaria ventralis) \\
\hline 6 & Ventral sac, left & Middle of the left side (same distance to the pila longitudinalis sinister and the pila coronaria ventralis) \\
\hline 7 & Ventral blind sac, right & Middle of the right side \\
\hline 8 & Ventral blind sac, left & Middle of the left side \\
\hline 9 & Dorsal sac, middle & Middle of the connecting line of the left and right sample \\
\hline
\end{tabular}


for which a stepwise forward approach was applied to achieve a numerically stable model. The $10 \%$ level of the partial $F$-statistic was applied as a threshold for exclusion of explanatory variables from the models, to retain tendencies. In all final models, weaning method was maintained independently of significance level. We examined the assumption of normally distributed errors and homoscedasticity graphically by using a quantilequantile plot (residual quantiles vs. quantiles of normal distribution) and a Tukey-Anscombe plot (residual vs. estimates). Except for the health score, which was log-transformed, none of the response variables had to be transformed to satisfy statistical assumptions. All calculations were done with S-Plus software (version 6.2; Insightful Corp., Palo Alto, CA).

Health Status. To estimate the relation between health variables (health score, veterinary treatments, and proportion of days $\geq 39.5^{\circ} \mathrm{C}$ ), Spearman correlations were calculated using one value per variable and calf. To analyze the influence of the weaning method and feeding behavior on health status, a model for each of the 3 health variables was calculated [model A: health score; model B: veterinary treatments (yes/ no); and model C: proportion of days $\geq 39.5^{\circ} \mathrm{C}$; Table $3]$. For each of these models, the explanatory variables were the weaning method (concentrate-dependent/conventional), breed (Swiss Brown/Holstein-Friesian/Red Holstein), amount of concentrate consumed $(\mathrm{kg} / \mathrm{d})$, duration of hay feeding (min/6-h observation), and number of decreases in concentrate and milk consumption. Animals nested in replicates were included in all 3 models as random effects.

Weight Gain. Model D was calculated to test for the effect of the 3 health parameters and the weaning method on weight gain (g/animal per day; Table 3 ). The model included weaning method (concentrate-dependent/conventional), breed (Swiss Brown/HolsteinFriesian/Red Holstein), proportion of days with body temperature $\geq 39.5^{\circ} \mathrm{C}$, health score, number of veterinary treatments, and decreases in concentrate and milk consumption as explanatory variables. Animals nested in replicates were included as random effects.

Rumen Development. Papillae length (models E1 to E8: one model per area) was investigated by using weaning method (concentrate-dependent/conventional), weight gain (g/animal per day), breed (Swiss Brown/ Red Holstein), concentrate intake (kg/animal), and duration of hay feeding (min/animal per 3 observation days) as explanatory variables. Random effects of papillae nested in tissue samples nested in animals nested in replicate were included to reflect the experimental design. To ensure that none of the continuous explanatory variables covaried strongly with weaning method, the influence of weaning method on concentrate con-

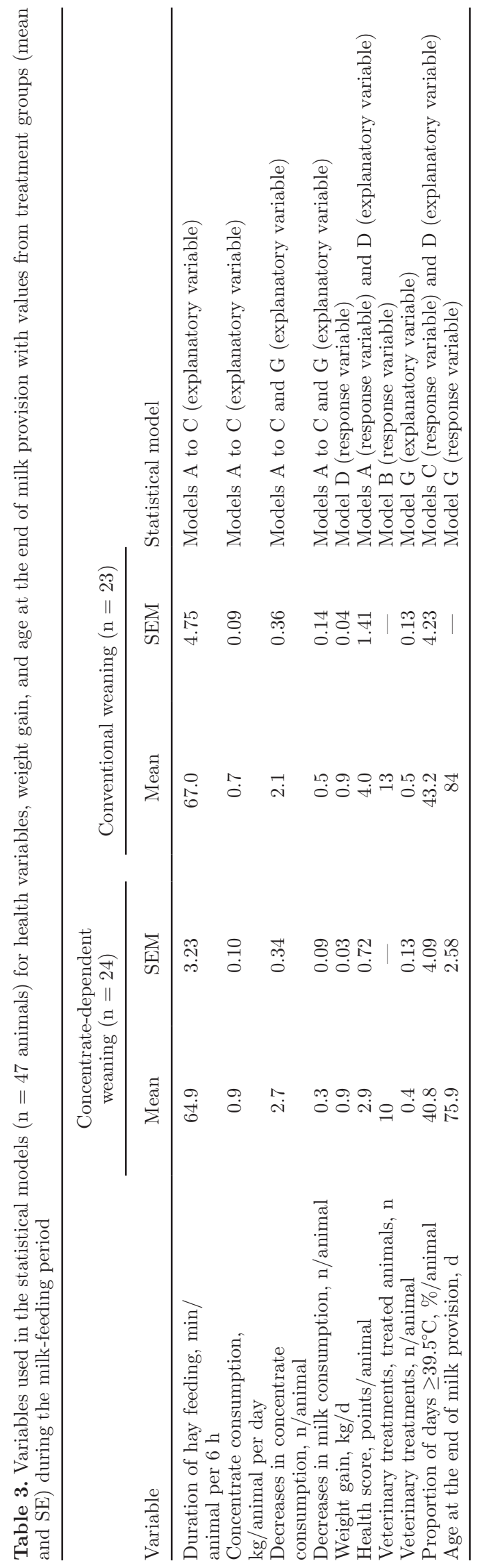

Journal of Dairy Science Vol. 92 No. 2, 2009 


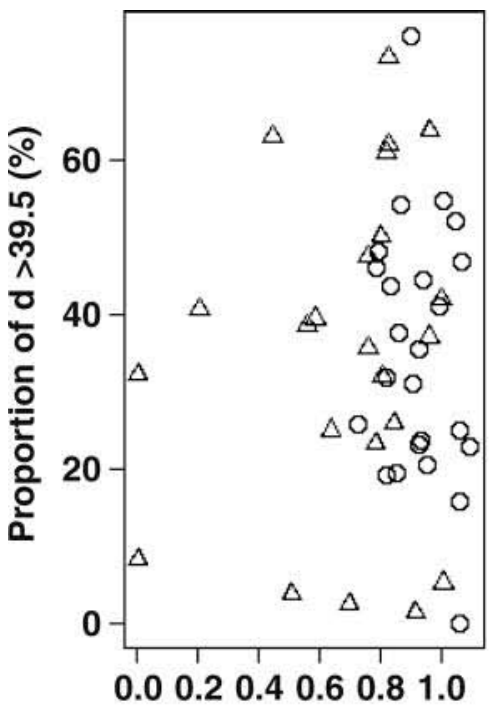

Concentrate consumption $(\mathbf{k g})$

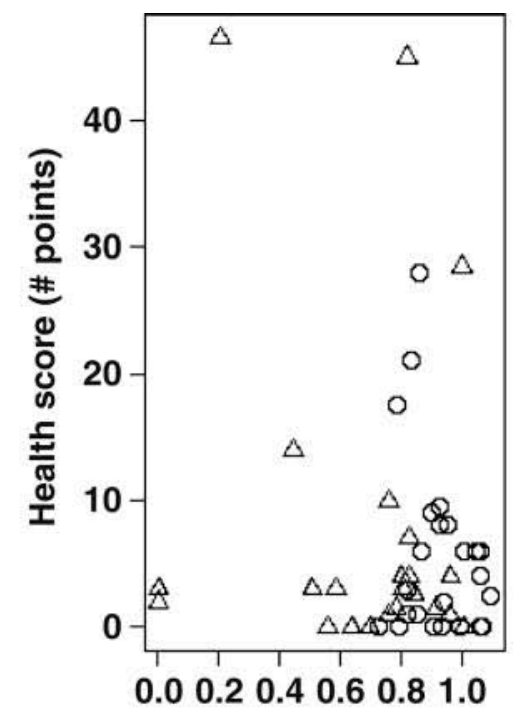

Concentrate consumption $(\mathrm{kg})$

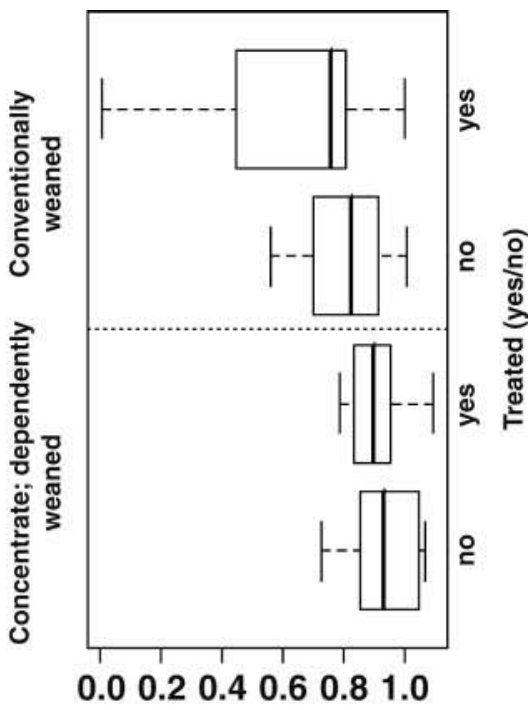

Concentrate consumption $(\mathbf{k g})$

Figure 3. Relation of health parameters and concentrate intake: average daily concentrate consumption and a) proportion of days $\geq 39.5^{\circ} \mathrm{C}$ $(\%), b)$ health score (points, n), and c) the dichotomous variable of treatment by a veterinarian (yes/no) for calves weaned by the concentratedependent method $(O)$ and the conventional method $(\Delta)$.

sumption, duration of hay feeding, age at slaughtering, and weight gain was tested (generalized linear models, with animals nested in replicates as random effects). A significant influence could be found only for age at slaughtering $(P=0.008)$. This parameter was thus not used for models E1 to E8. Separately, to check the influence of age at slaughtering on papillae length, models F1 to F8 for each area were calculated with this single explanatory variable. For this, we used the subset of calves weaned by the concentrate-dependent method because age at slaughtering varied only in this treatment group. Random effects were papillae nested in tissue sampling nested in animals and replicate.

Age at the End of Milk Provision. For conventionally weaned calves, age at the end of milk provision was set to $84 \mathrm{~d}$, independently of concentrate consumption and decreases in consumption. To see whether the age at the end of milk provision differed between the 2 treatment groups, a Wilcoxon signed-rank test was used to compare age at the end of milk provision for calves weaned by the concentrate-dependent method with the fixed value of $84 \mathrm{~d}$ for conventionally weaned calves.

In model G (Table 3), we investigated which factors influenced age at the end of milk provision in calves weaned by the concentrate-dependent method. We included the effect of breed (Swiss Brown/Holstein-Friesian/Red Holstein), proportion of days $\geq 39.5^{\circ} \mathrm{C}$, health score, number of veterinary treatments, and number of decreases in concentrate and milk consumption during the milk-feeding period. Animals nested in replicates were included as random effects.

\section{RESULTS}

\section{Health Status}

Correlations Between Health Variables. Health score correlated moderately with the number of veterinary treatments $(\mathrm{r}=0.49)$ and the proportion of days $\geq 39.5^{\circ} \mathrm{C}(\mathrm{r}=0.48)$. The proportion of days $\geq 39.5^{\circ} \mathrm{C}$ correlated less with the number of veterinary treatments $(\mathrm{r}=0.38)$.

Health Score. Health scores of $2.9( \pm 0.72)$ and $4.0( \pm 1.41)$ points were given to calves weaned by the concentrate-dependent and conventional methods, respectively, during the milk-feeding period (Table 3). Health score (model A) decreased with increasing concentrate $\left(\mathrm{F}_{1,44}=21.56, P<0.001\right.$; Figure 3$)$ and hay consumption $\left(F_{1,44}=5.48, P<0.024\right)$, and decreased as the number of decreases in concentrate consumption increased $\left(F_{1,44}=4.41, P=0.041\right)$. No influence of the weaning method on health score was found $\left(F_{1,44}=\right.$ $0.00, P=0.986)$.

Veterinary Treatments. A total of $49 \%$ of all animals were treated at least once (at most 5 treatments/ animal) by a veterinarian. In total, respiratory diseases had to be treated 38 times (conventional weaning: 20 treatments; concentrate-dependent weaning: 18 treatments) and diarrhea had to be treated 3 times (conven- 
tional weaning: 2 treatments; concentrate-dependent weaning: 1 treatment). Fourteen calves weaned by the concentrate-dependent method and 10 calves weaned by the conventional method were never treated by a veterinarian. The probability of being treated by a veterinarian at least once (model B) was elevated if less concentrate was consumed $\left(t_{45}=-5.80, P<0.001\right.$; Figure 3) or if the number of decreases in concentrate consumption increased $\left(t_{45}=-3.82, P<0.001\right)$. No influence of weaning method on veterinary treatments was found $\left(t_{44}=0.23, P=0.816\right)$.

Proportion of Days $\geq 39.5^{\circ} \mathrm{C}$. During the entire milk-feeding period, a body temperature of $39.5^{\circ} \mathrm{C}$ or more was observed on $40.8 \%$ ( 0 to $96 \%$ ) and $43.2 \%$ (0 to 100\%) of all the days for calves weaned by the concentrate-dependent method and the conventional method, respectively (Table 3 ). The proportion of days $\geq 39.5^{\circ} \mathrm{C}$ (model $\mathrm{C}$ ) decreased with increasing concentrate intake $\left(F_{1,36}=56.90, P<0.001\right.$; Figure 3$)$ and duration of hay feeding $\left(F_{1,36}=4.30, P=0.045\right)$. Furthermore, Swiss Brown calves had a greater proportion of days $\geq 39.5^{\circ} \mathrm{C}$ than did the other 2 breeds $\left(F_{2,42}=\right.$ $4.55, P=0.016)$. No significant influence of weaning method on body temperature was found $\left(F_{1,42}=0.07\right.$, $P=0.787)$.

\section{Weight Gain}

During the milk-feeding period, calves weaned by the concentrate-dependent method gained, on average, 0.88 $\mathrm{kg} / \mathrm{d}( \pm 0.03)$ and calves weaned by the conventional method gained $0.87 \mathrm{~kg} / \mathrm{d}( \pm 0.04)$. Weight gain (model D) decreased with an increasing number of veterinary treatments $\left(F_{1,35}=11.76, P=0.002\right)$, proportion of days $\geq 39.5^{\circ} \mathrm{C}\left(F_{1,35}=87.47, P<0.001\right)$, and number of decreases in milk consumption $\left(F_{1,35}=4.13, P=\right.$ 0.050). No significant influence of weaning method on weight gain was found $\left(F_{1,44}=0.00, P=0.987\right)$.

\section{Rumen Development}

Depending on the region, hay consumption, concentrate consumption, weight gain, and the weaning method had a significant impact on rumen development. The effect of hay consumption on papilla length was different between regions. In area 2 , papillae were longer with greater hay consumption $\left(F_{1,19}=3.91, P\right.$ $=0.063)$, and in areas 1,3 , and 5 they were shorter (area 1: $F_{1,19}=3.31, P=0.089$; area $3: F_{1,20}=5.21, P$ $=0.034$; area $\left.5: F_{1,19}=3.46, P=0.079\right)$. Longer papillae were observed to correlate with greater concentrate consumption in areas 2 and 4 (area 2: $F_{1.19}=13.88$, $P=0.001$; area $\left.4: F_{1,20}=10.95, P=0.004\right)$, but not in other areas. In contrast, the relationship between papillae length and weight gain was rather consistent, because good weight gain was associated with longer papillae in 4 of 8 regions (area 1: $F_{1,19}=5.11, P=$ 0.036 ; area $5: F_{1,19}=4.72, P=0.043$; area $7: F_{1,20}=$ $3.11, P=0.093$; area 8: $F_{1.20}=3.46, P=0.078$; Figure 4). No effect of breed was found.

Calves weaned by the concentrate-dependent method tended to have longer papillae than conventionally weaned calves in area 6 (model E6, $F_{1,21}=3.26, P=$ $0.085)$. However, no differences were found in papillae length between calves weaned by the concentrate-dependent and conventional methods in any of the other areas (Table 4).

Standard deviations of papillae length on all levels of nesting are summarized in Table 5. In most areas, standard deviations of papillae levels were nearly as great as or greater than standard deviations between animals.

A significant influence on papillae length for age of calves weaned by the concentrate-dependent method at slaughtering (models F1 to F8) could be shown only for area $1\left(F_{1,9}=5.36, P=0.046\right)$. No other areas showed a significant difference (area $2: F_{1,9}=1.33, P=0.279$; area 3: $F_{1,9}=0.14, P=0.713$; area $4: F_{1,9}=0.49, P=$ 0.501 ; area $5: F_{1,9}=0.09, P=0.774$; area $6: F_{1,9}=0.43$, $P=0.530 ;$ area $7: F_{1,9}=0.84, P=0.385 ;$ area $8: F_{1,9}$ $=0.29, P=0.603)$.

\section{Age at the End of Milk Provision, Feeding Behavior, and Economics}

The average age at the end of milk provision of calves weaned by the concentrate-dependent method was 76 $\mathrm{d}$, which was younger than the fixed age of $84 \mathrm{~d}$ for conventionally weaned calves (Wilcoxon, $Z=-2.89, P$ $=0.004)$. Age at the end of milk provision for calves weaned by the concentrate-dependent method ranged from 45 to $98 \mathrm{~d}$, with the maximum age being $14 \mathrm{~d}$ greater than that for conventionally weaned calves. Age at the end of milk provision for calves weaned by the concentrate-dependent method (model G) increased with an increase in the number of veterinary treatments $\left(F_{1,20}=4.97, P=0.038\right)$, and tended to be greater as the number of declines in concentrate consumption increased $\left(F_{1,20}=3.20, P=0.089\right)$. Decreases in milk consumption were rarely observed in either treatment group. Decreases in concentrate and milk consumption are summarized in Table 3.

The acquisition costs for the automatic milk-feeding and concentrate systems amounted to approximately $€ 12,790$ (\$18,700) for 24 animals ( $€ 7,440$ for the automatic milk feeder, $€ 2,000$ for the temperature measurement equipment, €2,800 for the concentrate feeder, and $€ 550$ for the Kalbmanager software plus interface). 
Table 4. Variables used in the statistical models $(\mathrm{n}=24$ animals $)$ for rumen development, with values from treatment groups (mean and SE) from grouping until slaughtering (3 wk after the end of milk provision)

\begin{tabular}{lccccc}
\hline & \multicolumn{2}{c}{ Concentrate-dependent weaning } & & \multicolumn{2}{c}{ Conventional weaning } \\
\cline { 2 - 3 } \cline { 5 - 5 } Variable & Mean & SEM & & Mean & SEM \\
\hline Explanatory & & & & \\
Duration of hay feeding, min/animal & 219.8 & 14.75 & & 224.8 & 21.83 \\
Concentrate consumption, kg/animal & 74.7 & 1.48 & & 66.9 & 6.35 \\
Weight gain, kg/d & 1.0 & 0.03 & & 0.9 & 0.07 \\
Response & & & & \\
Papillae length, mm & 3.3 & 0.16 & & 3.2 & 0.30 \\
Area 1 & 3.7 & 0.19 & & 3.6 & 0.27 \\
Area 2 & 0.9 & 0.09 & & 0.8 & 0.15 \\
Area 3 & 4.2 & 0.30 & & 4.4 & 0.48 \\
Area 4 & 2.0 & 0.09 & & 2.2 & 0.18 \\
Area 5 & 2.9 & 0.16 & & 2.3 & 0.24 \\
Area 6 & 2.4 & 0.16 & 2.2 & 0.26 \\
Area 7 & 2.1 & 0.15 & 2.1 & 0.15 \\
Area 8 & & & & \\
\hline
\end{tabular}

These prices correspond to the German market. The consumption of milk replacer by calves weaned on the concentrate-dependent method amounted to $19.3 \mathrm{~kg} /$ calf, and for conventionally weaned calves, it amounted to $23.1 \mathrm{~kg} /$ calf. Concentrate consumption from grouping until the end of milk provision for calves weaned by the concentrate-dependent method was $36.2 \mathrm{~kg} /$ calf, and for conventionally weaned calves, it was $38.4 \mathrm{~kg} /$ calf. On average, calves weaned by the concentratedependent method cost 126.40 Swiss francs (\$128.30) per calf and conventionally weaned calves cost 146.80 Swiss francs (\$149.00) per calf (again from grouping at $30 \mathrm{~d}$ of age until the end of milk provision), reflecting a $7.2 \%$ reduction in the requirement per calf.
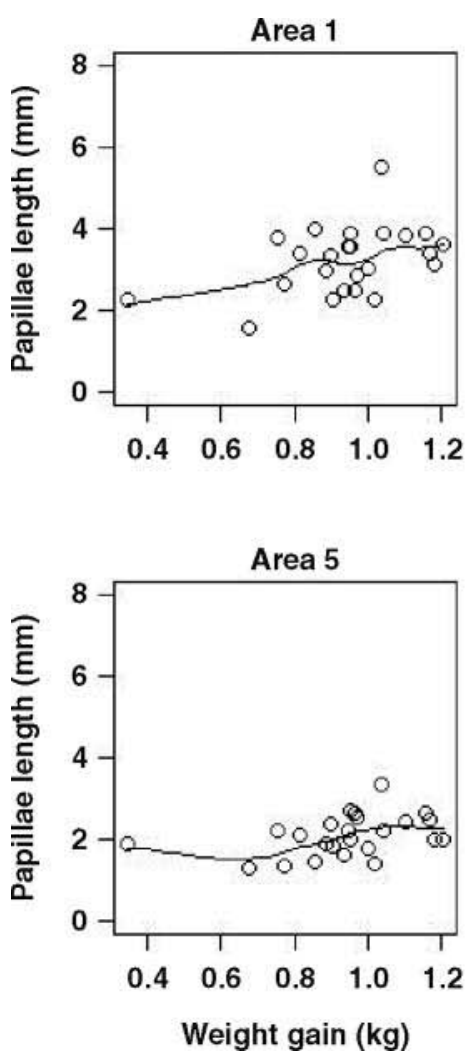

Area 2

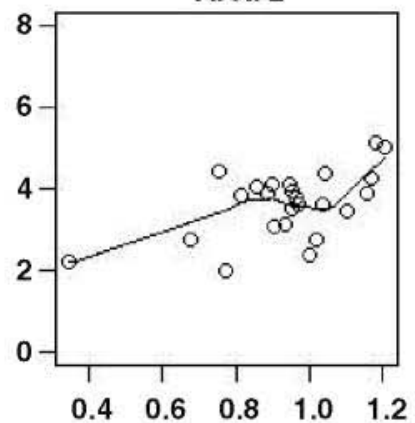

Area 6

Area 3

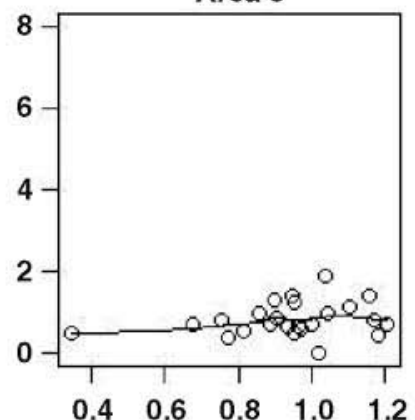

Area 7

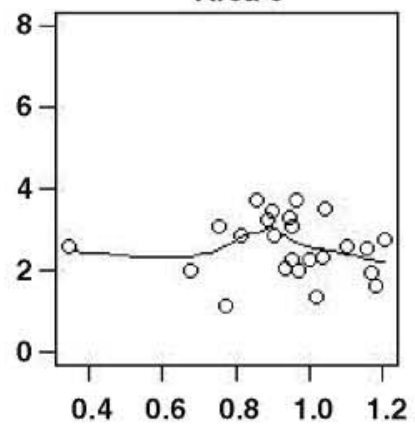

Weight gain $(\mathrm{kg})$

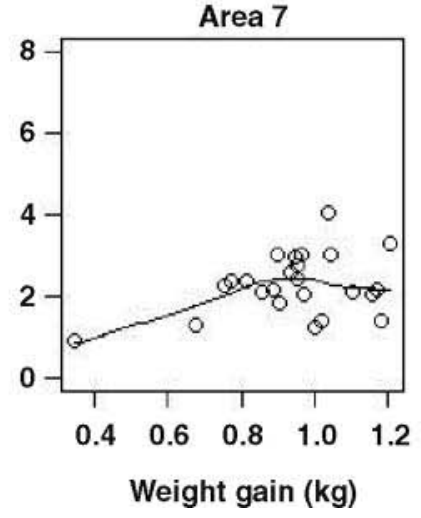

Area 4

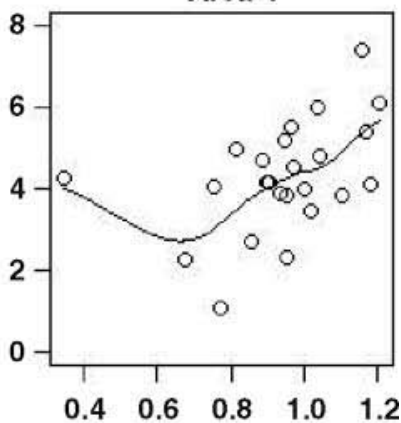

Area 8

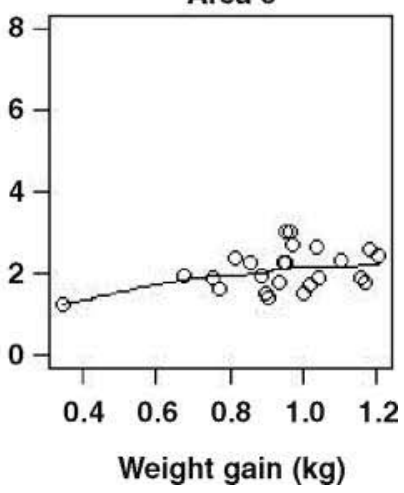

Figure 4. Mean length of rumen papillae (of each animal) versus weight gain in all 8 rumen areas. A significant association was found in regions $1,5,7$, and 8 . 


\section{DISCUSSION}

By analyzing data on the health status, weight gain, rumen development, and feeding behavior of 47 male dairy calves during the milk-feeding period until $3 \mathrm{wk}$ after the end of milk provision, we showed that a poor health status negatively affected weight gain. During the milk-feeding period, body temperature was elevated for more than $40 \%$ of all days, and sick animals reduced their solid food intake. Rumen development was positively associated with weight gain. By comparing 2 different weaning methods, we could also demonstrate that the concentrate-dependent weaning method led to a younger age at the end of milk provision without a negative impact on weight gain or rumen development, compared with the conventional weaning method.

\section{Assessing Health Status}

In our study, $49 \%$ of all animals were treated by a veterinarian at least once, and animals had a fever on more than $40 \%$ of all the days during the milk-feeding period. This proportion is fairly high, but not unusual, for farming practice (Quigley et al., 2006; Svensson and Liberg, 2006) and underlines the high risk that is associated with regrouping of calves of very young age originating from different farms. Illness in dairy calves results in not only a slowed physiological development (e.g., reduced weight gain and solid food intake), but also an economic loss. Detection of a sick animal out of an entire group as early as possible should be the main focus of caretakers because it will most likely shorten the duration of illness, decrease the strain on the affected animal, and reduce medical costs.

Correlations Between Health Variables. The correlations between health variables were rather moderate. This underlines the difficulty of assessing health status reliably by using only one indicator. The body temperature of all animals was elevated on more than $40 \%$ of all the days, which indicates that the animals were ill much more frequently than was noticed based on visual inspection. Therefore, automatically measuring body temperature by using a feeding computer should be a tool caretakers can use to spot a susceptible animal, even before it becomes visibly ill. This should not replace the daily visual check by the caretakers, but could aid caretakers in spotting sick animals before illness becomes severe. Combined with additional parameters (e.g., feed intake; see further discussion), we are confident that data from automatic milk and concentrate feeders are useful tools to support the assessment of health status of an individual level.

Feeding Behavior, Weight Gain, and Health Status. Computer-controlled (milk and concentrate)
Table 5. Standard deviations of all 8 final models of rumen analysis subdivided by animals, samplings, and papillae according to the nesting in the statistical models

\begin{tabular}{lccc}
\hline Rumen area & Animals & Samplings & Papillae \\
\hline Area 1 & 0.639 & 0.335 & 0.595 \\
Area 2 & 0.555 & 0.550 & 0.586 \\
Area 3 & 0.377 & 0.134 & 0.154 \\
Area 4 & 1.062 & 0.786 & 0.858 \\
Area 5 & 0.403 & 0.317 & 0.425 \\
Area 6 & 0.666 & 0.350 & 0.507 \\
Area 7 & 0.642 & 0.577 & 0.461 \\
Area 8 & 0.332 & 0.610 & 0.459 \\
\hline
\end{tabular}

feeders provide several advantages. The computercontrolled feeders can provide several (and therefore smaller) meals per day and per animal, and the individual consumption is registered automatically. These registered data can provide valuable information on the health status of the individual animal. Furthermore, in comparison with bucket feeding, automatic milk feeders provide the possibility of sucking on the artificial teat, which is important for calves to allow for a healthy digestion. Decreases in milk consumption were rarely observed, and no significant relationship was found between decreases in milk consumption and health status. Thus, decreases in milk consumption are not suitable to assess health status because the amount of milk provided is consumed even by a calf with poor health status. Therefore, using reduced milk consumption measures to screen for ill calves would identify these animals much too late. However, almost all animals demonstrated a diminished intake of solid feed during illness, as revealed by the relationship between reduced hay and concentrate consumption, and health variables. This reduction of solid food intake during illness also has been observed in other studies (Radostits, 2001). Therefore, diminished concentrate consumption and decreases in concentrate consumption seem to be suitable indicators of illness. In contrast to hay consumption, these parameters can be detected easily by analyzing data from the feeding computer.

As expected, weight gain also reflected the health status of the animals (elevated body temperature and veterinary treatments). However, assessment of the current health status by weight gain would seem to be suitable only if exact weight gain could be measured automatically and continuously on a daily basis. Furthermore, because decreased weight gain is mainly the result of diminished feed intake, it is reasonable to assume that monitoring this parameter would allow a faster response time for treating sick animals.

For disease detection in scientific research as well as for use in practice, we recommend assessing body temperature and changes in concentrate consumption individually. Automatic measurement by the feeding 
computer seems to be a meaningful and time-saving method to minimize the strain from illness for the animals. We did not measure frequency of unrewarded visits to the milk feeder, but Svensson and Jensen (2007) additionally suggested that this could be a sensitive indicator of illness. To reduce the high disease prevalence in young calves, in our view it would be worthwhile to attend to this topic in further studies. Investigation of which combinations of parameters are the best predictors for disease detection would lead to earlier identification and treatment of ill calves, thereby reducing the number of days spent ill or diminishing the severity of symptoms, or both.

\section{Rumen Development}

The consistent relationship between weight gain and papillae length in 4 of 8 regions showed that weight gain was a rather accurate and easily measurable predictor of rumen development. Papillae length in our study was longer compared with papillae length in other studies (e.g., Lesmeister et al., 2004; Khan et al., 2007a, 2008), but our animals were several weeks older at slaughtering. Although earlier studies showed that solid food intake was positively correlated with papillae growth (e.g., Tamate et al., 1962), we found an influence of hay and concentrate consumption on rumen development for some, but not all, rumen regions in our data. This might be explained by the fact that all our animals received solid food of appropriate quality, which could have been of sufficient quantity to initiate rumen development. Because milk amounts were rather small, animals were encouraged to consume solid food, and indeed, only 3 animals from the conventionally weaned group consumed only low levels $(<0.5 \mathrm{~kg} / \mathrm{d})$ during the milk-feeding period.

On the other hand, there is still a lack of knowledge about how to measure rumen development reliably. A few repeatable sampling methods for analyzing rumen development are described in the literature (e.g., rumen $\mathrm{pH}, \mathrm{BHBA}$, and VFA, and by collecting rumen fluid or blood; see Coverdale et al., 2004; Lesmeister and Heinrichs, 2004; Suàrez et al., 2006; Khan et al., 2008). However, a clear interrelationship among all these parameters and rumen development has not been shown until now, because rumen differentiation has not been entirely understood (Baldwin et al., 2004). Furthermore, the measurement of parameters by obtaining rumen fluid from young calves has also been connected to practical problems. A pilot study with our calves revealed that collecting rumen fluid disturbed solid food intake for several days, which was an unacceptable effect of our study. Therefore, analysis of the rumen after slaughter is likely to be the most accurate way to characterize rumen development. Several studies analyzed only small numbers of papillae (e.g., Cozzi et al., 2002; Kristensen et al., 2007). The comparison of standard deviations among papillae, samplings, and animals in our study revealed that variation between papillae of the same animal was nearly as great as variation between animals. This demonstrates that a large number of papillae need to be analyzed to achieve reliable results.

The disadvantage of this method is that it reflects only the condition of a preceding process and does not allow for repeated measures of rumen development over time. Another reason for the rather weak correlation between papillae length and feeding parameters in our study could be that slaughtering took place too late after the end of milk provision. It has to be assumed that in the $3 \mathrm{wk}$ after the end of milk provision, the rumen of the calves developed further, which might have masked differences between calves weaned by the concentrate-dependent and conventional methods that could have been detected directly at the end of milk provision.

\section{Effects of Weaning Method}

In contrast to our expectations, calves weaned by the concentrate-dependent method were not healthier than conventionally weaned calves. One reason for this could be that, in this respect, our study design was unfavorable because calves in both treatments were kept in the same group, which easily enabled the spreading of pathogens. Thus, in the end the risk of becoming ill was the same for all animals, so the weaning method was without influence. Although we did not record disease duration, it may be possible for the concentrate-dependent weaning method to be helpful for a diseased calf by enabling a faster recovery from illness. In calves on concentrate-dependent weaning, decreases in concentrate consumption and the proportion of days $\geq 39.5^{\circ} \mathrm{C}$ were related to a prolonged time to the end of milk provision. The individual feeding plan was able to compensate for a delay in rumen development, which is generally caused by illness (Radostits, 2001). Only in calves weaned by the concentrate-dependent method did a reduction in concentrate consumption result in an increase in the milk amount provided. Thus, in the case of illness (and reduced intake of solid food), these calves were not additionally burdened by a reduction in milk amount. The observation that calves weaned by the concentrate-dependent method were $8 \mathrm{~d}$ younger at the end of milk provision than conventionally weaned calves supports this argument.

Average weight gain in general was comparable to or slightly greater than values in other studies for 
both groups (Coverdale et al., 2004; Lesmeister and Heinrichs, 2004; Lesmeister et al., 2004; Khan et al., $2007 \mathrm{~b}, \mathrm{c})$. We had expected that calves weaned by the concentrate-dependent method would grow faster than conventionally weaned calves (Roth et al., 2008) and have a better rumen development. However, this was not the case, because weight gain was the same for both treatment groups, and at slaughtering papillae length tended to differ between treatment groups only in one rumen region. But again, the calves in concentrate-dependent weaning developed faster and were, on average, weaned $8 \mathrm{~d}$ earlier than conventionally weaned calves. This difference is economically relevant because of reduced costs for the expensive milk replacer in calves weaned by the concentrate-dependent method. The price for milk replacer and concentrate differs largely between Switzerland and other countries. Additionally, Swiss feeding regimens for calves (i.e., age at weaning) are managed differently in comparison with many other countries.

Except for one region, in calves weaned by the concentrate-dependent method, age had no effect on rumen development. The large range in age at the end of milk provision of calves in concentrate-dependent weaning reflected differences in the developmental capacity to feed and digest dry food. Therefore, we strongly recommended applying an individually adapted weaning curve to satisfy the nutritional needs of each calf in a group.

\section{CONCLUSIONS}

The high proportion of sick animals reflects a need for improving the health of calves in artificial rearing. Solid food consumption and body temperature seem to be good indicators for the early detection of diseases, which can be done automatically by using an automatic feeding station. Health status, weight gain, and rumen development did not differ in calves weaned by the concentrate-dependent method and the conventional method, but calves weaned by the concentrate-dependent method were weaned at a younger age without any negative implications for production.

\section{ACKNOWLEDGMENTS}

We are grateful to Marc Wymann and Urs Marolf for care of the animals. We also thank FA Foerster-Technik GmbH (Engen, Germany) for the helpful cooperation. Special thanks goes to Heike Schulze Westerath (ETH Zurich) for her help with the rumen analysis, and to Bruno Joerg and Daniel Boesch (ETH Zurich) for their help with the rumen sampling. We are also grateful to Markus Stauffacher (ETH Zurich) for fruitful dis- cussions. Finally, we are grateful to the anonymous reviewer for his valuable comments on the manuscript. The study was supported by Agroscope ReckenholzTaenikon Research Station ART in Taenikon (Ettenhausen, Switzerland), ETH Zurich, and the Federal Veterinary Office (Berne, Switzerland, project no. 2.05.03).

\section{REFERENCES}

Baldwin, R. L. V. I., K. R. McLeod, J. L. Klotz, and R. N. Heitmann. 2004. Rumen development, intestinal growth and hepatic metabolism in the pre- and postweaning ruminant. J. Dairy Sci. 87(E Suppl.):E55-E65.

Coverdale, J. A., H. D. Tyler, J. D. Quigley III, and J. A. Brumm. 2004. Effect of various levels of forage and from of diet on rumen development and growth in calves. J. Dairy Sci. 87:2554-2562.

Cozzi, G., F. Gottardo, S. Mattiello, E. Canali, E. Scanziani, M. Verga, and I. Andrighetto. 2002. The provision of solid feeds to veal calves: I. Growth performance, forestomach development, and carcass and meat quality. J. Anim. Sci. 80:357-366.

Curtis, C. R., H. N. Erb, and M. E. White. 1988. Descriptive epidemiology of calfhood morbidity and mortality in New York Holstein herds. Prev. Vet. Med. 5:293-307.

Gibb, D. J., K. S. Schwartzkopf-Genswein, J. M. Stookey, J. J. McKinnon, D. L. Godson, R. D. Wiedmeier, and T. A. McAllister. 2000. Effect of a trainer cow on health, behavior, and performance of newly weaned beef calves. J. Anim. Sci. 78:1716-1725.

Harsch, E. 2002. Vergleich der Rektaltemperatur zur automatisch gemessenen Zungentemperatur bei Kälbern am Tränkeautomat. Diplomarbeit, Fachhochschule Nürtingen, Nürtingen, Germany.

Hepola, H. 2003. Milk feeding systems for dairy calves in groups: Effects on feed intake, growth and health. Appl. Anim. Behav. Sci. 80:233-243.

Keil, N. M., and W. Langhans. 2001. The development of intersucking in dairy calves around weaning. Appl. Anim. Behav. Sci. 72:295308.

Khan, M. A., H. J. Lee, W. S. Lee, H. S. Kim, K. S. Ki, T. Y. Hur, G. H. Suh, S. J. Kang, and Y. J. Choi. 2007a. Structural growth, rumen development, and metabolic and immune responses of Holstein male calves fed milk through step-down and conventional methods. J. Dairy Sci. 90:3376-3387.

Khan, M. A., H. J. Lee, W. S. Lee, H. S. Kim, S. B. Kim, K. S. Ki J. K. Ha, H. G. Lee, and Y. J. Choi. 2007b. Pre- and postweaning performance of Holstein female calves fed milk through step-down and conventional methods. J. Dairy Sci. 90:876-885.

Khan, M. A., H. J. Lee, W. S. Lee, H. S. Kim, S. B. Kim, K. S. Ki, S. J. Park, J. K. Ha, and Y. J. Choi. 2007c. Starch source evaluation in calf starter: I. Feed consumption, body weight gain, structural growth, and blood metabolites in Holstein calves. J. Dairy Sci. 90:5259-5268.

Khan, M. A., H. J. Lee, W. S. Lee, H. S. Kim, S. B. Kim, S. B. Park, K. S. Baek, J. K. Ha, and Y. J. Choi. 2008. Starch source evaluation in calf starter: II. Ruminal parameters, rumen development, nutrient digestibilities, and nitrogen utilization in Holstein calves. J. Dairy Sci. 91:1140-1149.

Kirchgessner, M. 2004. Tierernährung: Leitfaden für Studium, Beratung und Praxis. 11th ed. DLG-Verlag, Frankfurt am Main, Germany.

Kristensen, N. B., J. Sehested, S. K. Jensen, and M. Vestergaard. 2007. Effect of milk allowance on concentrate intake, ruminal environment, and ruminal development in milk-fed Holstein calves. J. Dairy Sci. 90:4346-4355.

Lesmeister, K. E., and A. J. Heinrichs. 2004. Effects of corn processing on growth characteristics, rumen development, and rumen parameters in neonatal dairy calves. J. Dairy Sci. 87:3439-3450.

Lesmeister, K. E., P. R. Tozer, and A. J. Heinrichs. 2004. Development and analysis of a rumen tissue sampling procedure. J. Dairy Sci. 87:1336-1344. 
Lundborg, G. K., E. C. Svensson, and P. A. Oltenacu. 2005. Herd-level risk factors for infectious diseases in Swedish dairy calves aged 0-90 days. Prev. Vet. Med. 68:123-143.

Quigley, J. D., T. A. Wolfe, and T. H. Elsasser. 2006. Effects of additional milk replacer feeding on calf health, growth, and selected blood metabolites in calves. J. Dairy Sci. 89:207-216.

Rademacher, G. 2003. Kälberkrankheiten-Ursachen und Früherkennung, Neue Wege für Vorbeugung und Behandlung. 2nd ed. Verlag Eugen Ulmer, Stuttgart, Germany.

Radostits, O. M. 2001. Herd Health: Food Animal Production Medicine. 3rd ed. W.B. Saunders Company, Philadelphia, PA.

Roth, B. A., E. Hillmann, M. Stauffacher, and N. M. Keil. 2008. Improved weaning reduces cross-sucking and may improve weight gain in dairy calves. Appl. Anim. Behav. Sci. 111:251-261.

Suàrez, B. J., C. G. Van Reenen, W. J. J. Gerrits, N. Stockhofe, A. M. van Vuuren, and J. Dijkstra. 2006. Effects of supplementing concentrates differing in carbohydrate composition in veal calf diets: II. Rumen development. J. Dairy Sci. 89:4376-4386.

Svensson, C., and M. B. Jensen. 2007. Short communication: Identification of diseased calves by use of data from automatic milk feeders. J. Dairy Sci. 90:994-997.
Svensson, C., and P. Liberg. 2006. The effect of group size on health and growth rate of Swedish dairy calves housed in pens with automatic milk-feeders. Prev. Vet. Med. 73:43-53.

Svensson, C., K. Lundborg, U. Emanuelson, and S. Olsson. 2003 Morbidity in Swedish dairy calves from birth to 90 days of age and individual calf-level risk factors for infectious diseases. Prev. Vet. Med. 58:179-197.

Swiss Federal Research Station for Animal Production. 1999. Fütterungsempfehlungen und Nährwerttabellen für Wiederkäuer. 4th ed. Landwirtschaftliche Lehrmittelzentrale, Zollikofen, Switzerland.

Tamate, H., A. D. McGilliard, N. L. Jacobson, and R. Getty. 1962. Effect of various dietaries on the anatomical development of the stomach in the calf. J. Dairy Sci. 45:408-420.

Weber, R., and B. Wechsler. 2001. Reduction in cross-sucking in calves by the use of a modified automatic teat feeder. Appl. Anim. Behav. Sci. 72:215-223. 